\title{
Escherichia coli heat-shock proteins IbpA/B are involved in resistance to oxidative stress induced by copper
}

\begin{abstract}
Correspondence
Ewa Laskowska

lasko@biotech.ug.gda.pl
\end{abstract}

Received 6 November 2007

Revised 12 March 2008

Accepted 17 March 2008

\author{
Ewelina Matuszewska, Joanna Kwiatkowska, Dorota Kuczyńska-Wiśnik \\ and Ewa Laskowska
}

Department of Biochemistry, University of Gdańsk, Kładki 24, 80-952 Gdańsk, Poland

\section{INTRODUCTION}

IbpA and IbpB proteins were identified for the first time as components of inclusion bodies formed in Escherichia coli cells overproducing heterologous proteins (Allen et al., 1992). It was also demonstrated that during heat stress, $\mathrm{IbpA} / \mathrm{B}$ localize to the fraction of denatured and aggregated E. coli proteins (Laskowska et al., 1996). IbpA and IbpB share about $50 \%$ amino acid homology and belong to the ubiquitous family of small heat-shock proteins (sHsps) or $\alpha$-heat-shock proteins ( $\alpha$-Hsps) characterized by low molecular mass $(12-30 \mathrm{kDa})$ and a conserved C-terminal ' $\alpha$-crystallin' domain (Narberhaus, 2002; Haslbeck et al., 2005). $\alpha$-Crystallin is a mammalian eye lens sHsp which prevents protein aggregation and is responsible for maintaining transparency of the lens. sHsps form oligomers comprising between 9 and 50 subunits, depending on the particular sHsp. Some sHsps have a defined oligomeric structure with a fixed number of subunits; others, like $\alpha$ crystallins and IbpA/B, form polydisperse oligomers (Haslbeck et al., 2005; Nakamoto \& Vigh, 2007). sHsps bind denatured proteins and facilitate their refolding by the ATP-dependent molecular chaperones of the Hsp70 family (Haslbeck et al., 2005). In E. coli cells, the substrates bound to $\mathrm{IbpA} / \mathrm{B}$ are refolded by $\mathrm{DnaK}$ and its co-chaperones DnaJ and GrpE in cooperation with the $\mathrm{AAA}^{+}$protein ClpB (Veinger et al., 1998; Mogk et al., 2003a, b; Matuszewska et al., 2005). The lack of IbpA/B proteins results in increased aggregation of heat-denatured proteins

Abbreviations: DNP, 2,4-dinitrophenol; DNPH, 2,4-dinitrophenylhydrazine; Hsp, heat-shock protein; MCO, metal-catalysed oxidation; ROS, reactive oxygen species; sHsp, small heat-shock protein. in E. coli cells. However, the phenotype of $\triangle i b p A / B$ mutation is only observed under severe heat stress $\left(50{ }^{\circ} \mathrm{C}\right)$ (Kuczyńska-Wiśnik et al., 2002) or at lower heatshock temperature $\left(45^{\circ} \mathrm{C}\right)$ in the double mutant $\triangle i b p A /$ $B \Delta c l p B$, and in $\triangle i b p A / B$ cells with downregulated DnaK/ DnaJ levels (Mogk et al., 2003a). It was also reported that removal of aggregated proteins at a recovery temperature of $30{ }^{\circ} \mathrm{C}$ was delayed in the absence of IbpA/B (Mogk et al., 2003a; Jiao et al., 2005). Both IbpA and IbpB are required during substrate inactivation in vitro, to efficiently stabilize denatured protein in a folding-competent state (Matuszewska et al., 2005). It is known that IbpA and IbpB interact in vitro; however, the nature of cooperation between IbpA and IbpB is not fully understood. Some in vivo and in vitro data suggest that IbpA may be responsible for targeting $\mathrm{IbpB}$ to denatured and aggregated proteins (Kuczyńska-Wiśnik et al., 2002; Matuszewska et al., 2005).

$\mathrm{IbpA} / \mathrm{B}$ have been suggested to participate in the defence of E. coli cells against oxidative stress. It was demonstrated that bacteria overproducing $\mathrm{IbpA} / \mathrm{B}$ proteins acquired resistance to superoxide stress (Kitagawa et al., 2000); moreover IbpA/B suppressed inactivation of selected enzymes by hydrogen peroxide and potassium superoxide in vitro (Kitagawa et al., 2002). It was also found that an $i b p A / B$-deficient strain showed increased sensitivity to superoxide radicals generated by tellurite (Pérez et al., 2007).

In this study we investigated the role of IbpA/B proteins in protection of $E$. coli against oxidative stress induced by copper ions. Copper is an essential transition metal required as a cofactor for numerous respiratory and 
metabolic enzymes, mainly those that utilize dioxygen or reactive oxygen species (ROS); however, copper is toxic even at low concentrations (Silver \& Phung, 2005; Kershaw et al., 2005). At present, knowledge on the toxicity of copper is limited. Excess copper may compete with other essential transition metals for binding to the active sites of metalloproteins and catalyse formation of non-native disulfide bonds in proteins, resulting in perturbation of protein function (Hiniker et al., 2005). Copper changes the permeability and fluidity of membranes and affects conductance of ionic channels (Suwalsky et al., 1998; Avery et al., 1996). The mechanism of copper cytotoxicity also includes generation of highly toxic hydroxyl radicals (Kershaw et al., 2005) and other ROS (Tree et al., 2005; Macomber et al., 2007). In this process, $\mathrm{Cu}^{2+}$ and $\mathrm{Cu}^{+}$ ions react with superoxide anion and hydrogen peroxide, which are byproducts of aerobic metabolism that are present at low, non-toxic concentrations in E. coli cells (Storz \& Imlay, 1999). The level of superoxide anions may be increased via reaction of $\mathrm{Cu}^{+}$ions with molecular oxygen:

$$
\begin{aligned}
& \mathrm{Cu}^{2+}+\mathrm{O}_{2}^{\bullet-} \leftrightarrow \mathrm{Cu}^{+}+\mathrm{O}_{2} \\
& \mathrm{Cu}^{+}+\mathrm{H}_{2} \mathrm{O}_{2} \rightarrow \mathrm{Cu}^{2+}+{ }^{\bullet} \mathrm{OH}+\mathrm{OH}^{-}
\end{aligned}
$$

ROS generated by copper may damage proteins, DNA and lipids. It should be noted that copper toxicity increases under anaerobic conditions, when ROS are not produced; this may result from the increased reduction of $\mathrm{Cu}^{2+}$ to more toxic $\mathrm{Cu}^{+}$ions (Outten et al., 2001).

In this paper we demonstrate that IbpA/B contribute to the tolerance of $E$. coli to copper under aerobic conditions. We report evidence that $\mathrm{IbpA} / \mathrm{B}$ protect proteins from coppermediated oxidation both in vivo and in vitro.

\section{METHODS}

Bacterial strains and growth conditions. E. coli MC4100 [araD139 $\triangle$ (lacIPOZYA $\operatorname{argF}$ )U169 fla relA $r p s L]$ used as a wild-type (WT) strain, E. coli MC4100 $\triangle i b p A / B:$ : cm (Kuczyńska-Wiśnik et al., 2002), E. coli MC4100 $\triangle c l p B:$ kan (Geuskens et al., 1992) and E. oli MC4100 $\Delta$ dnaK52:: cat (Mogk et al., 1999) were grown at $30{ }^{\circ} \mathrm{C}$ in Luria broth (LB) supplemented with $0.2 \%$ glucose, aerobically, in flasks with shaking (200 r.p.m.) or anaerobically, without shaking, in bottles filled to the top.

Purification of proteins for in vitro tests. After prolonged incubation of E. coli under oxygen depletion, AdhE forms large active oligomers which can be isolated from bacterial cell extracts by ultracentrifugation (Matayoshi et al., 1989; Kessler et al., 1992); therefore, we applied a one-step AdhE purification method. After testing different growth conditions, we found that almost homogeneous enzyme could be isolated from $E$. coli cells growing microaerobically at $25{ }^{\circ} \mathrm{C}$, in $\mathrm{M} 9$ minimal medium with $0.2 \%$ glucose. AdhE was purified from MC4100 $i b p A / B$ cultures $(250 \mathrm{ml})$, incubated without shaking in $250 \mathrm{ml}$ Erlenmeyer flasks for $68 \mathrm{~h}$. Bacteria were collected, resuspended in $0.2 \mathrm{M}$ Tris/ $\mathrm{HCl} \mathrm{pH} \mathrm{8.0,} \mathrm{converted} \mathrm{to}$ spheroplasts and sonicated as described previously (Kucharczyk et al., 1991). Cell lysates $(6 \mathrm{ml})$ were incubated with $2 \%$ Triton X-100 at room temperature for $15 \mathrm{~min}$ and loaded on a two-step sucrose gradient $(1 \mathrm{ml} 55 \%, \mathrm{w} / \mathrm{w}$, sucrose and $5 \mathrm{ml} 17 \%$, w/w, sucrose in
$3 \mathrm{mM}$ EDTA pH 8.0). AdhE oligomers were pelleted by ultracentrifugation at $200000 \mathrm{~g}$, for $1.5 \mathrm{~h}$. The pellet was resuspended in $10 \mathrm{mM}$ Tris/ $\mathrm{HCl} \mathrm{pH} 8.0$ and immediately used for the experiments. IbpA and IbpB proteins were purified as described previously (Matuszewska et al., 2005). Protein concentration was determined by the method of Bradford (1976) using BSA as a standard.

Detection of protein-bound carbonyl groups. The bacteria were collected, washed in $10 \mathrm{mM}$ Tris/ $\mathrm{HCl} \mathrm{pH} 8.0$, resuspended in buffer A (0.5 M Tris/HCl pH 6.8, 6\% SDS, $10 \mathrm{mM}$ EDTA) and lysed at $95{ }^{\circ} \mathrm{C}$ for $5 \mathrm{~min}$. Aliquots of extracts containing equal amounts of protein were derivatized with $10 \mathrm{mM}$ 2,4-dinitrophenylhydrazine (DNPH) in $2 \mathrm{M} \mathrm{HCl}$ for $30 \mathrm{~min}$ at room temperature. After neutralization with $2 \mathrm{M} \mathrm{NaOH}$, proteins were dissolved in Laemmli (1970) lysis buffer, separated by SDS-PAGE and transferred to a nitrocellulose membrane. Protein-bound 2,4-dinitrophenylhydrazones were visualized using anti-2,4-dinitrophenol (DNP) antibodies (Sigma) and ECL Western blotting detection reagents (Pierce Biotechnology).

AdhE oxidation in vitro and AdhE activity assay. Oxidation of AdhE $(0.4 \mu \mathrm{M})$ in vitro was performed at room temperature in $0.15 \mathrm{mM}$ potassium phosphate buffer $\mathrm{pH} 7.4$ containing $0.2 \mathrm{mM}$ $\mathrm{CuCl}_{2}$ and $2 \mathrm{mM}$ ascorbate (Stadtman, 1991). AdhE activity was measured spectrophotometrically at $340 \mathrm{~nm}$ in a reaction mixture containing $0.66 \mathrm{mM} \mathrm{NADH}, 1.6 \mathrm{M}$ ethanol and $0.3 \mathrm{M}$ potassium carbonate buffer $\mathrm{pH} 10$. A unit of enzyme activity is defined as $1 \mathrm{nmol}$ of NADH produced $\min ^{-1}$ (Echave et al., 2002). To determine AdhE activity in cell extracts, bacteria were pelleted, resuspended in $10 \mathrm{mM}$ Tris/ $\mathrm{HCl} \mathrm{pH} 7.5$ and disrupted by sonication.

SDS-PAGE and immunoblotting. Gel electrophoresis was performed according to standard protocols (Laemmli, 1970). Immunodetection of proteins was carried out using antisera specific for protein-bound dinitrophenylhydrazones (Sigma), IbpA/B or AdhE as primary antibodies (Kuczyńska-Wiśnik et al., 2002), with anti-rabbit IgG horseradish peroxidase conjugate (Sigma) and ECL detection reagents (Pierce Biotechnology). Membranes were scanned and analysed with the 1DScan EX program (Scanalytics).

\section{RESULTS}

\section{Copper tolerance in the $E$. coli $\triangle i b p A / B$ strain is decreased under aerobic conditions}

To investigate whether IbpA/B participate in the protection of $E$. coli cells against the toxic effects of copper, we first compared the sensitivity of the WT and $\triangle i b p A / \mathrm{B}$ strains to $\mathrm{Cu}^{2+}$ and analysed the level of $\mathrm{IbpA} / \mathrm{B}$ proteins in E. coli cells exposed to copper. We found that indeed $\Delta i b p A / B$ cells showed increased sensitivity to $\mathrm{Cu}^{2+}$ (Fig. 1a). As expected, the amount of IbpA/B proteins increased (10fold) and reached the maximum after $1-2 \mathrm{~h}$ of $\mathrm{Cu}^{2+}$ treatment (Fig. 1d). The 2D-PAGE used for separation of the IbpA from IbpB revealed that the IbpA:IbpB molar ratio was 1.6:1 (data not shown). Further incubation of the WT strain in the presence of $\mathrm{Cu}^{2+}$ resulted in a gradual decline in the amount of IbpA/B to the basal level at the end of the experiment. The described phenotype of the $\triangle i b p A / B$ mutation was observed only under aerobic conditions. In the absence of oxygen, the toxicity of copper increased significantly (Fig. 1b) in agreement with 


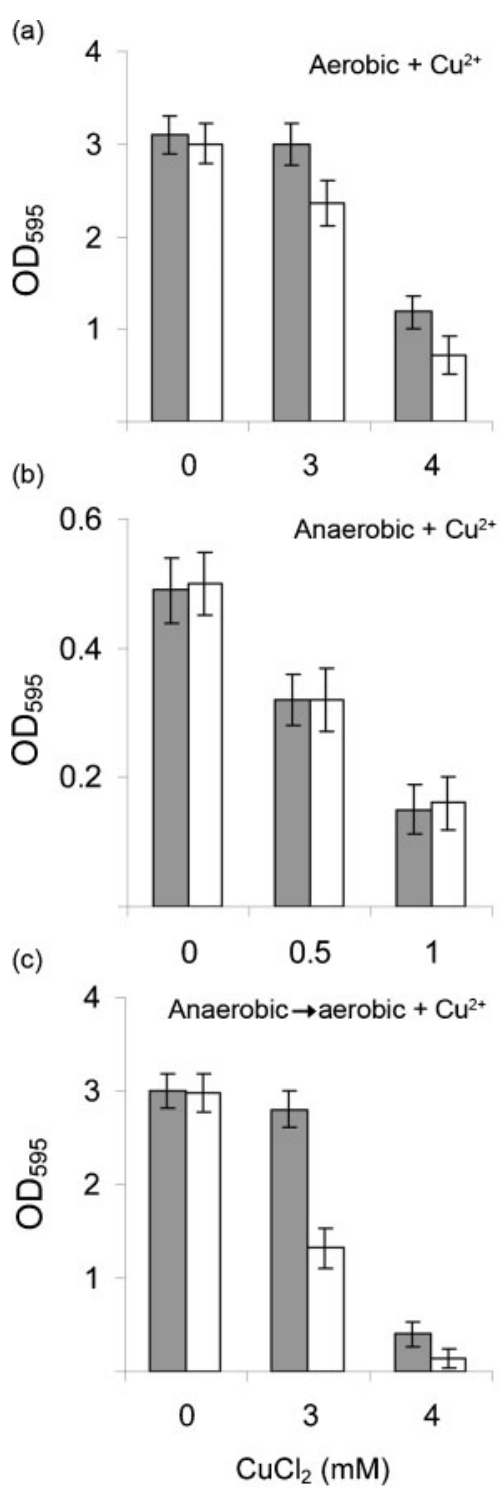

(d)

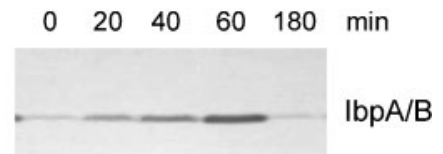

Fig. 1. Lack of $\mathrm{lbpA} / \mathrm{B}$ chaperones increases sensitivity of aerobically growing $E$. coli to $\mathrm{Cu}^{2+}$. MC4100 WT (grey bars) and MC4100 $\triangle i b p A / B$ (white bars) were grown aerobically (a) or anaerobically $(\mathrm{b}, \mathrm{c})$ at $30^{\circ} \mathrm{C}$. The anaerobic cultures shown in (b) were grown in the presence of the indicated amounts of $\mathrm{CuCl}_{2}$ from inoculation. Other cultures (a and $\mathrm{c}$ ) were supplemented with $\mathrm{CuCl}_{2}$ at an $\mathrm{OD}_{595}$ of 0.2. Simultaneously, anaerobically growing cells (c) were transferred to flasks for aerobic incubation. Final optical density was measured after $18 \mathrm{~h}$ of incubation. The data correspond to the means $\pm S D$ of three independent experiments. (d) $\mathrm{Cu}^{2+}$ induces production of $\mathrm{lbpA}$ and $\mathrm{lbpB}$ proteins in $E$. coli cells. IbpA and $\mathrm{lbpB}$ were detected in the samples taken from the WT cultures treated with $4 \mathrm{mM} \mathrm{CuCl}_{2}$ at the indicated time points. Proteins were separated by SDS-PAGE and immunodetected using anti-lbpA/B serum and ECL reagents. Both $\mathrm{lbpA}$ and $\mathrm{lbpB}$ migrated in the polyacrylamide gel as one band. published results (Outten et al., 2001). However, we did not observe any remarkable differences in growth between the $\mathrm{WT}$ and $\triangle i b p A / B$ strains (Fig. 1b). These results suggest that $\mathrm{IbpA} / \mathrm{B}$ may suppress toxicity of copper by protection of cells against ROS whose production is induced by $\mathrm{Cu}^{2+}$. Further data indirectly supported this assumption: a more severe phenotype of the $\triangle i b p A / B$ mutation was observed when copper treatment in the presence of oxygen was preceded by anaerobic incubation of the cultures (Fig. 1c). In this experiment, the effect of copper treatment was enhanced by oxidative stress initiated by the shift of the cultures from anaerobic to aerobic conditions.

One of the types of damage caused by ROS in cells is oxidation of proteins, resulting in the formation of carbonyl groups in some amino acid residues. To determine whether IbpA/B protect E. coli proteins from oxidation by ROS, we compared the degree of protein carbonylation in the WT and $\triangle i b p A / B$ strains exposed to copper stress (Fig. 2). After $30 \mathrm{~min}$ of $\mathrm{Cu}^{2+}$ treatment, the level of oxidized proteins increased 2-fold and 2.5-fold in aerobically growing WT and $\triangle i b p A / B$ cells, respectively (Fig. 2a). During further incubation in the presence of copper, the levels of carbonylated proteins decreased to the initial amounts. This was in agreement with the observation that oxidized proteins are rapidly removed from the cell by proteolysis (Nyström, 2005). Therefore after prolonged treatment with $\mathrm{Cu}^{2+}$, removal of oxidized proteins proceeded faster than protein carbonylation. Elevated protein oxidation was also detected in bacteria untreated with $\mathrm{Cu}^{2+}$ that were shifted from anaerobic to aerobic conditions (Fig. 2b). In this case, the level of carbonylated proteins was comparable in both the WT and $\triangle i b p A / B$ strains. At the end of the experiment, bacteria entered the stationary phase, in which accumulation of an increased amount of oxidized proteins has been noted previously (Dukan \& Nyström, 1998). Copper treatment after the shift from anaerobic to aerobic conditions caused a further enhancement of protein oxidation. After $30 \mathrm{~min}$, the amount of carbonylated proteins in $\triangle i b p A / B$ cells was only slightly higher compared to the WT strain. However, in the absence of IbpA/B the level of carbonylated proteins decreased at a slower rate (Fig. 2c). The above results taken together indicate that $\mathrm{IbpA} / \mathrm{B}$ inhibit protein oxidation and/or facilitate degradation of oxidatively damaged proteins under copper stress.

\section{IbpA/B protect AdhE from metal-catalysed oxidation in vivo and in vitro}

One of the oxidized proteins, visible as a dominant band immunostained with anti-DNP antibodies (Fig. 2d), was further identified as AdhE by immunodetection (data not shown). AdhE is a $\mathrm{Fe}^{2+}$-dependent protein with the activity of alcohol dehydrogenase and acetaldehyde-CoA dehydrogenase (Membrillo-Hernández et al., 2000; Nnyepi et al., 2007). AdhE converts acetyl-CoA to acetaldehyde, and then to ethanol in NADH-dependent reactions. The 
(a)

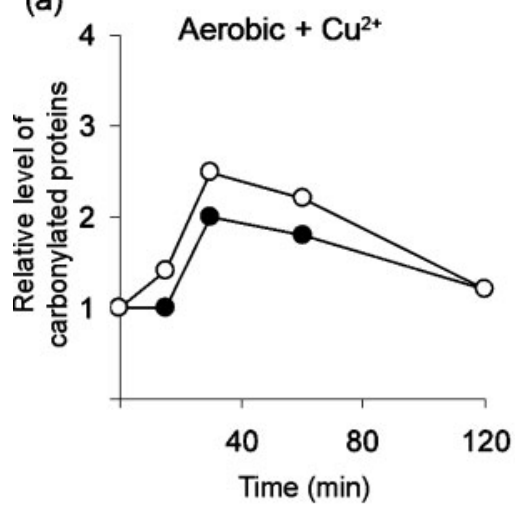

(b)

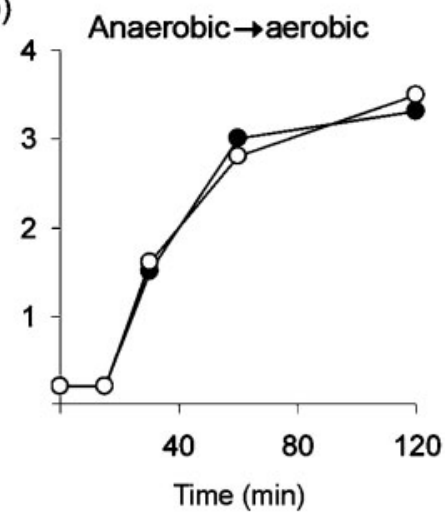

(c)

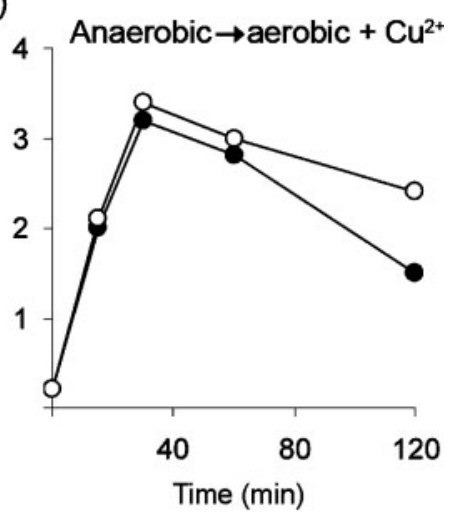

(d)

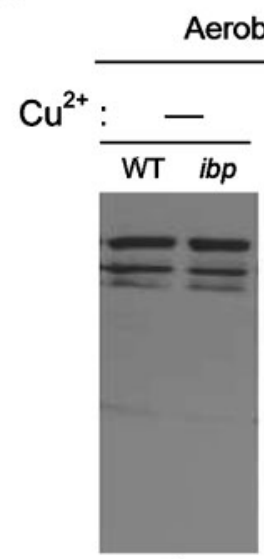

0

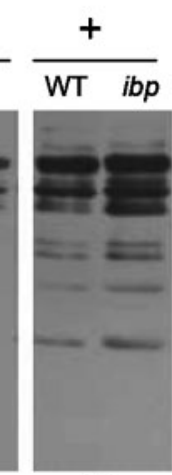

60

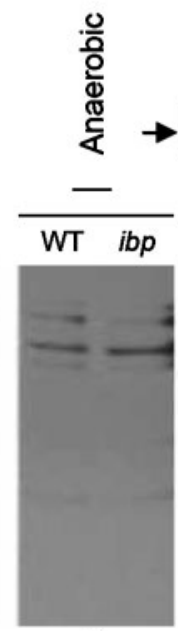

0

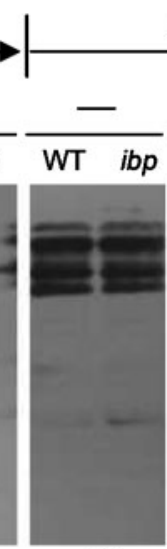

60

Aerobic

$\frac{+}{W T \quad i b p} \frac{+}{W T \quad i b p}$

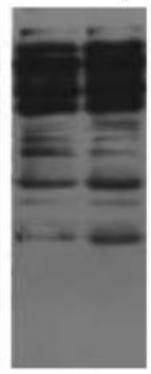

60

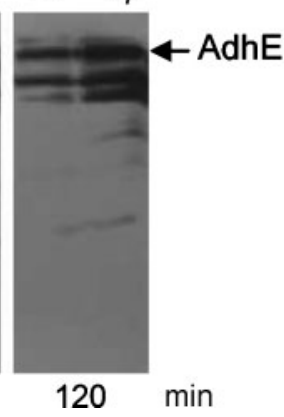

Fig. 2. Protein oxidation induced by $\mathrm{Cu}^{2+}$ is increased in the absence of $\operatorname{lbpA} / \mathrm{B}$. E. coli WT $(\mathbf{O})$ and $\Delta i b p A / B(\bigcirc)$ strains were grown aerobically (a) or anaerobically at $30{ }^{\circ} \mathrm{C}$ to an $\mathrm{OD}_{595}$ of 0.2 . The anaerobically growing bacteria were transferred to flasks and split into two samples (b and c). One of the samples was treated with $4 \mathrm{mM} \mathrm{CuCl}_{2}(\mathrm{c})$. $\mathrm{CuCl}_{2}(4 \mathrm{mM})$ was also added to the aerobic cultures (a). At the indicated time points, bacteria were harvested and proteins were derivatized with DNPH (see Methods). Samples containing equal amounts of protein were resolved by SDS-PAGE and analysed by immunoblotting using anti-DNP antibody. The level of carbonylated proteins was estimated by densitometry (a-c). (d) Western blotting results showing the protein carbonylation pattern in selected samples. AdhE protein is indicated by an arrow. The data are representative and similar results were obtained in two other experiments.

adhE gene is very highly expressed under anaerobic conditions. After the shift of bacteria to aerobic conditions, expression of the gene is inhibited and AdhE is inactivated by metal-catalysed oxidation (MCO). In this process, $\mathrm{Fe}^{2+}$ ions react with $\mathrm{H}_{2} \mathrm{O}_{2}$ to generate hydroxyl radicals, which covalently attack the amino acid residues near the metalbinding site (Cecarini et al., 2007). Our result showing that AdhE is one of the main proteins oxidized in $\mathrm{Cu}^{2+}$-treated cells (Fig. 2d) is in good agreement with the observation that AdhE is one of the major targets of hydrogen peroxide stress (Tamarit et al., 1998).

We investigated the effect of IbpA/B on in vivo inactivation of AdhE after the shift of cultures to aerobic conditions (Fig. 3). It was found previously that in the presence of oxygen, AdhE is protected against MCO by DnaK, but not $\mathrm{ClpB}$ chaperone (Echave et al., 2002); therefore, in our experiment $\Delta d n a K$ and $\Delta c l p B$ strains were used as controls. Since a decrease of AdhE activity might result from both MCO and degradation of the enzyme, the amount of AdhE protein in bacteria was also monitored by Western blotting using anti-AdhE antibodies with serial dilutions of purified AdhE as standards (data not shown). We determined AdhE concentration and its activity and calculated specific AdhE activity expressed as units of AdhE $\mathrm{mg}^{-1}$. This allowed comparison of the degree of AdhE inactivation in different strains regardless of the rate of AdhE degradation. In nonstressed anaerobic WT and $\Delta i b p A / B$ cultures, $7500 \pm 200 \mathrm{U}$ AdhE $\mathrm{mg}^{-1}$ was detected and set to $100 \%$. After $1 \mathrm{~h}$ of aerobic growth, $90 \%$ of AdhE specific activity was detected 
in WT and $\Delta c l p B$, whereas in the absence of $\mathrm{IbpA} / \mathrm{B}$ and DnaK the specific activity of AdhE decreased to $20 \%$ and to $10 \%$, respectively (Fig. 3). Thus, IbpA/B, similarly to DnaK chaperone, inhibited aerobic inactivation of AdhE. However, the levels of carbonylated AdhE immunodetected in the WT and $\triangle i b p A / B$ cultures shifted to aerobic conditions were comparable (Fig. 2d). This may indicate that oxidized and inactivated AdhE is removed faster in $\triangle i b p A / B$ than in WT cells. Indeed, the amount of total AdhE declined to approximately $40 \%$ in WT and to $30 \%$ in $\triangle i b p A / B$ cells (data not shown).

To confirm that $\mathrm{IbpA} / \mathrm{B}$ proteins prevent oxidation of AdhE we compared activities of the enzyme in the WT and $\triangle i b p A / B$ strains submitted to copper stress. In subsequent experiments, we used cultures that were incubated anaerobically and then exposed to copper, because a high initial level of AdhE was necessary for reliable activity measurements. The presence of $\mathrm{Cu}^{2+}$ ions during aerobic incubation resulted in accelerated inactivation of AdhE (Fig. 4a) in comparison with the previous experiment (Fig. 3). After $1 \mathrm{~h}$ incubation in the presence of copper, activity of AdhE dropped to $48 \%$ and $9 \%$ in WT and $\triangle i b p A / B$ strains, respectively. Again, the levels of carbonylated AdhE were comparable in both strains (Fig. 2d), indicating that damaged AdhE was removed faster in the absence of IbpA/ B. Indeed, the amount of total AdhE decreased in WT and $\triangle i b p A / B$ by $20 \%$ and $30 \%$ respectively (data not shown). Prolonged incubation $(2 \mathrm{~h})$ of WT and $\triangle i b p A / B$ bacteria in the presence of $\mathrm{Cu}^{2+}$ resulted in further proportional decrease of AdhE activities (Fig. 4a). The amounts of total

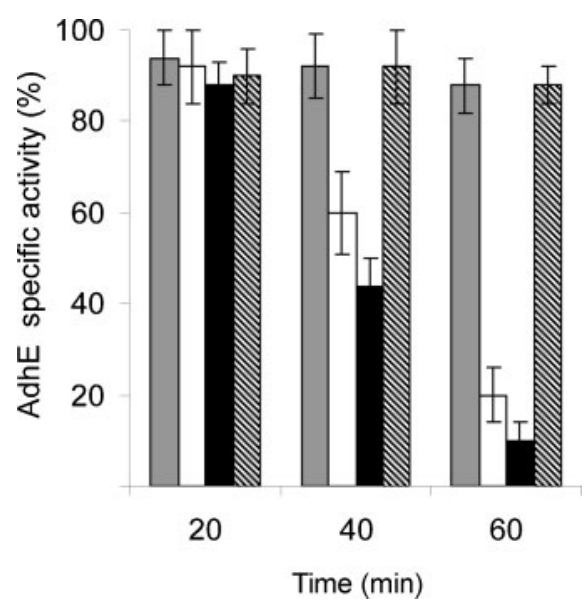

Fig. 3. $\mathrm{lbp} A / B$ protect $A d h E$ from inactivation after a shift from anaerobic to aerobic growth conditions. E. coli WT (grey bars), $\Delta i b p A / B$ (white bars), $\Delta d n a K$ (black bars) and $\Delta c / p B$ (striped bars) strains were grown anaerobically at $30{ }^{\circ} \mathrm{C}$ to an $\mathrm{OD}_{595}$ of 0.3 . The activity of AdhE was measured at the indicated time points after transferring bacterial cultures to flasks for aerobic incubation; $100 \%$ corresponds to AdhE activity before the shift $\left(7500 \pm 200 \mathrm{U}\right.$ AdhE $\left.\mathrm{mg}^{-1}\right)$. Means $\pm \mathrm{SD}$ of three independent experiments are shown.
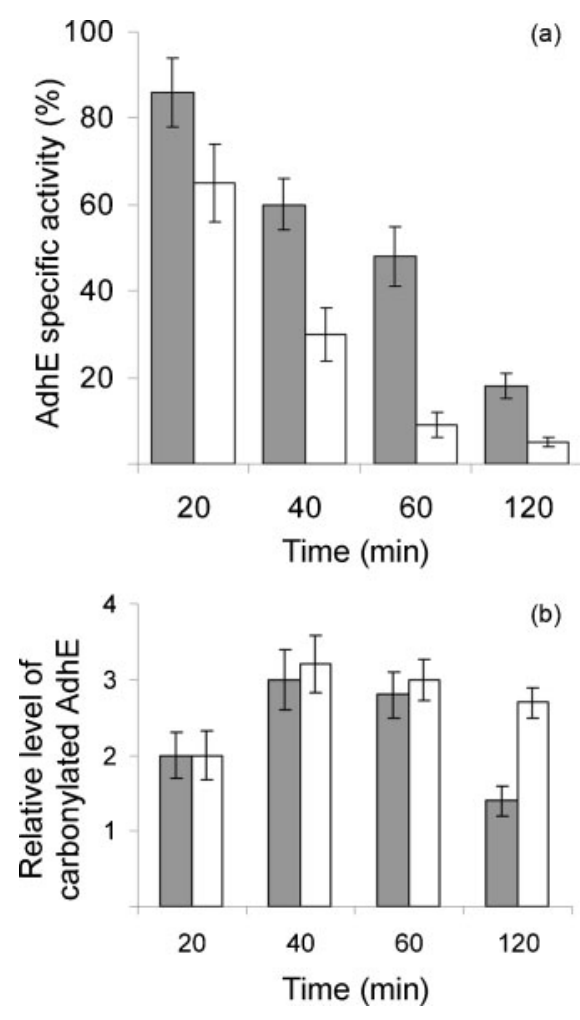

Fig. 4. $I b p A / B$ participate in protection of cellular AdhE against $\mathrm{Cu}^{2+}$-induced inactivation and carbonylation. (a) MC4100 WT (grey bars) and $\triangle i b p A / B$ cells (white bars) were cultured as described in the legend to Fig. 3. Immediately after the shift of the cultures to aerobic growth conditions, $\mathrm{CuCl}_{2}(4 \mathrm{mM})$ was added. AdhE activity was measured at the indicated times; $100 \%$ corresponds to AdhE activity before the shift $(7500 \pm 200 \mathrm{U}$ AdhE $\mathrm{mg}^{-1}$ ). (b) Relative amounts of carbonylated AdhE in the WT and $\triangle i b p A / B$ cells estimated from Fig. 2(d). The data correspond to the means \pm SD of three independent experiments.

AdhE did not change (not shown) in either strain but the fraction of carbonylated AdhE was apparently higher in the $\triangle i b p A / B$ strain (Fig. 4b). In summary, presented data demonstrated that IbpA/B inhibited inactivation of AdhE under oxidative stress induced by copper ions. It should be noted that inactivation of AdhE in vivo may result not only from the replacement of $\mathrm{Fe}^{2+}$ by $\mathrm{Cu}^{+}$and coppercatalysed oxidation, but also from direct modifications of amino acids by ROS produced in the presence of copper (Cecarini et al., 2007). Moreover, copper treatment may also increase the rate of $\mathrm{H}_{2} \mathrm{O}_{2}$ generation, which can accelerate iron-mediated AdhE inactivation. In order to confirm that IbpA/B prevent copper-catalysed oxidation of AdhE, we performed in vitro experiments with purified AdhE (Fig. 5a) and IbpA/B proteins. AdhE was oxidized in vitro by an ascorbate/ $\mathrm{Cu}^{2+}$ mixture (Stadtman, 1991) in the presence of IbpA, IbpB or both IbpA/B proteins (used at 1.6:1 molar ratio, as estimated in copper-stressed cells). After $3 \mathrm{~h}$ incubation at $25{ }^{\circ} \mathrm{C}$, AdhE activity was measured (Fig. 5b) and carbonylation of AdhE was analysed by 

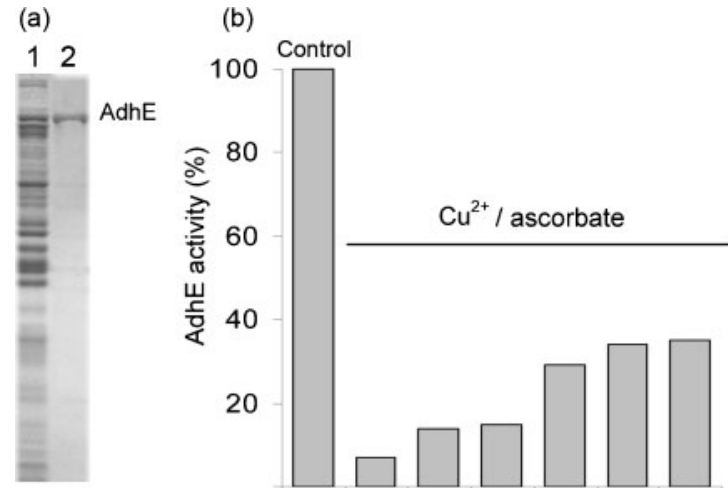

\begin{tabular}{|l|c|c|c|c|c|c|c|}
\hline IbpA & - & - & + & - & ++ & - & + \\
\hline IbpB & - & - & - & + & - & ++ & + \\
\hline
\end{tabular}

(c)

AdhE

IbpA/B

(d)

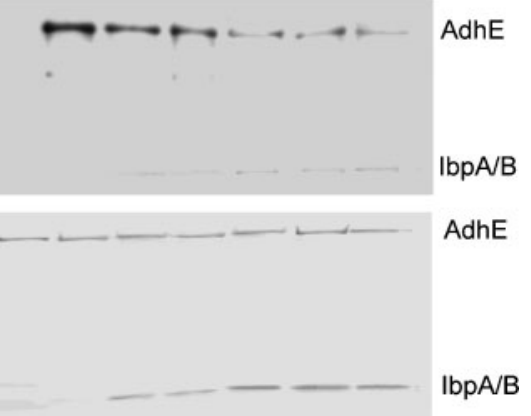

Fig. 5. $\mathrm{Ibp} A / B$ protect purified $\mathrm{AdhE}$ against $\mathrm{Cu}^{2+}$-induced inactivation and carbonylation. (a) Purified AdhE protein. Wholecell extract (lane 1) obtained from a microaerobic $\triangle i b p A / B$ culture (see Methods) and purified AdhE (lane 2) were separated by SDSPAGE and stained with Coomassie brilliant blue. (b) AdhE $(0.4 \mu \mathrm{M})$ was oxidized at room temperature in $0.15 \mathrm{M}$ potassium phosphate buffer $\mathrm{pH} 7.4$ containing $0.2 \mathrm{mM} \mathrm{CuCl} 2$ and $2 \mathrm{mM}$ ascorbate, in the absence or presence of $1 \mu \mathrm{M} \mathrm{IbpA}(+), 1 \mu \mathrm{M}$ $\operatorname{lbpB}(+), 2 \mu \mathrm{M} \operatorname{lbpA}(++), 2 \mu \mathrm{M} \operatorname{lbpB}(++)$ or both chaperones $(1.2 \mu \mathrm{M} \mathrm{lbpA}$ and $0.8 \mu \mathrm{M} \mathrm{lbpB})$. AdhE activity was measured after $3 \mathrm{~h}$ exposure of the enzyme to $\mathrm{Cu}^{2+}$ /ascorbate. (c) Carbonylation of AdhE and IbpA/B was analysed in duplicate samples by immunodetection, as described in the legend to Fig. 2. (d) AdhE and IbpA/B were resolved in a control polyacrylamide gel and stained with Coomassie brilliant blue. All experiments shown in $b-d$ were repeated three times and representative results are shown.

Western blotting (Fig. 5c). In the absence of chaperones, AdhE was almost completely inactivated and only $5 \%$ of the control AdhE activity was detected. The best efficiency of AdhE protection (30\% of the AdhE initial activity) was achieved in the samples containing fivefold molar excess of IbpA or IbpB, or both IbpA/B proteins $(1.2 \mu \mathrm{M}$ IbpA and $0.8 \mu \mathrm{M} \mathrm{IbpB}$ ) (Fig. 5b). Neither higher IbpA and IbpB concentrations, nor different IbpA: IbpB molar ratios improved the efficiency of protection (data not shown). Results obtained after estimation of AdhE carbonylation (Fig. 5c) were consistent with the activity assay. In the presence of optimal IbpA/B amounts, the level of carbonylated AdhE was fivefold lower than in the sample oxidized in the absence of the chaperones. The comparison of the intensities of immunodetected (Fig. 5c) and Coomassie-stained bands (Fig. 5d) indicated that the extent of IbpA/B carbonylation was much lower than that of AdhE. Taken together, these results showed that purified AdhE is protected from $\mathrm{Cu}^{2+}$-catalysed oxidation by IbpA and IbpB proteins.

\section{DISCUSSION}

The transition metal copper is an important cofactor for many enzymes. However, even moderately increased levels of copper may be highly toxic; therefore copper concentrations need to be regulated within narrow limits. Copper homeostasis in E. coli is controlled mainly by the efflux of excess copper out of the cell. The P-type ATPase CopA, embedded in the inner membrane, translocates $\mathrm{Cu}^{+}$from the cytoplasm and multicopper oxidase $\mathrm{CueO}$ converts periplasmic $\mathrm{Cu}^{+}$into less-toxic $\mathrm{Cu}^{2+}$. During anaerobic growth, copper toxicity increases and another efflux system encoded by the cusCFBA operon is necessary for full copper tolerance (Grass \& Rensing, 2001; Outten et al., 2001; Silver \& Phung, 2005). In the presence of high copper concentrations, when the efflux complexes are overloaded, E. coli cells activate general stress responses governed by the sigma factor RpoE (Egler et al., 2005) and the twocomponent signal transduction system CpxRA (Kershaw et al., 2005; Yamamoto \& Ishihama, 2005). Both pathways respond to environmental stresses and control expression of genes required for repairing of damaged proteins in the envelope (DiGiuseppe \& Silhavy, 2003). Recently, it was found that activity of the disulfide isomerase DsbC (Hiniker et al., 2005) and increased expression of the porin OmpC (Egler et al., 2005) are required for copper tolerance. DsbC rearranges non-native disulfide bonds formed in periplasmic proteins damaged by copper; the underlying mechanism of OmpC function remains unclear. DNA microarray experiments revealed that in response to superoxide stress as a secondary effect of excess copper, $E$. coli cells increase transcription of the SoxRS regulon (Kershaw et al., 2005; Yamamoto \& Ishihama, 2005). The above information indicates that $E$. coli copes with copper stress using several different mechanisms. In this report we present evidence that the $\mathrm{sHsps} \mathrm{IbpA} / \mathrm{B}$ constitute an additional element of the defence against copper toxicity. We demonstrated that the lack of $\mathrm{IbpA} / \mathrm{B}$ proteins increased sensitivity of aerobically growing $E$. coli to $\mathrm{Cu}^{2+}$ ions (Fig. 1a-c) and found that IbpA/B were induced by copper (Fig. 1d). In previous reports (Kershaw et al., 2005; Yamamoto \& Ishihama, 2005), the $i b p A / B$ operon was not found among copper-induced genes, probably because less harsh conditions (lower copper concentration or shorter time of exposure to copper) were applied compared to our experiments. IbpA/B may be the second line of defence, triggered in response to protein damage caused by copper in the cytoplasm. 
$\mathrm{IbpA} / \mathrm{B}$ proteins are markers of inclusion bodies and protein aggregates produced under heat stress or in trimethoprim-treated cells (Allen et al., 1992; Laskowska et al., 1996, 2003); thus it could be expected that similar protein aggregates were formed in the copper-stressed cells. This assumption is supported by the fact that introduction of carbonyl groups into proteins may induce intra- and intermolecular cross-links or conformational changes leading to formation of large aggregates resistant to proteolysis (Nyström, 2005; Cecarini et al., 2007). Such protein aggregates were not found either in WT or in $\triangle i b p A / B$ cells submitted to copper stress (data not shown). It is possible, however, that proteins damaged by copper formed smaller complexes which were soluble or could not be separated from the membranes by ultracentrifugation in a sucrose gradient. Indeed, we found that AdhE inactivated and oxidized by copper did not change its position in the sucrose gradient when compared to the native enzyme. Moreover, in the copper-treated WT cells, IbpA/B proteins were localized in the same fractions as AdhE (data not shown). It was demonstrated that in vitro solubility of sHsp complexes with substrate depends on the ratio of sHsp to substrate. The size of $\mathrm{sHsp} / \mathrm{substrate}$ complexes decreases as the ratio of sHsp to substrate increases (Mogk et al., 2003b). In other words, insoluble aggregates are formed when sHsps are overloaded with non-native substrates (Jiao et al., 2005). Apparently, this is not the case in the copper-treated cells. By contrast, protein aggregates containing $\mathrm{IbpA} / \mathrm{B}$ are formed in cells subjected to heat stress (Laskowska et al., 1996).

We showed that a possible mechanism of $\triangle i b p A / B$ copper sensitivity involves copper-induced carbonylation of proteins (Fig. 2). In vivo (Figs 3 and 4 ) and in vitro experiments (Fig. 5) revealed that $\mathrm{IbpA} / \mathrm{B}$ decreased oxidative inactivation and carbonylation of AdhE. The mechanism of protein protection by $\mathrm{IbpA} / \mathrm{B}$ remains to be elucidated. It can be expected that the overall ability of IbpA/B to protect cells from copper-induced damage may result from the metal binding and direct interaction with protected proteins, since a similar activity has been previously proposed for the mammalian sHsp homologue, $\alpha$-crystallin (Moschini et al., 2006). In addition, Ganadu et al. (2004) have shown that $\mathrm{Cu}^{2+}$ stably binds to $\alpha \mathrm{B}$-crystallin and elevates its chaperone-like activity. IbpA and IbpB were equally effective in protection of AdhE against copper-induced oxidation in vitro (Fig. 5). One must keep in mind that $\mathrm{IbpA}$ and $\mathrm{IbpB}$ may act in a different manner, by binding and protecting substrate or sequestering copper ions. This is possible, since it has been established that IbpA and IbpB exhibit different affinity for unfolded proteins (Kuczyńska-Wiśnik et al., 2002; Matuszewska et al., 2005).

Several papers on the role of Hsp in prevention of protein carbonylation have been published recently. Echave et al. (2002) found that DnaK protects AdhE against MCO. Fredriksson et al. (2005) reported that the molecular chaperones DnaK/DnaJ, GroEL/GroES and heat-shock proteases Lon and HslVU counteract protein carbonylation induced by stasis. Winter et al. (2005) demonstrated that the redox-regulated holdase Hsp33 protects proteins, including AdhE, against irreversible aggregation during oxidative heat stress. The authors found that DnaK is reversibly inactivated under oxidative heat stress due to a massive drop in intracellular ATP level caused by ROS. In consequence, ATP-independent Hsp33 is activated and takes over the protective role of DnaK. It is therefore conceivable that IbpA/B, which, like Hsp33, are ATPindependent chaperones, have a similar function.

AdhE is active as a dehydrogenase under anaerobic conditions. In the presence of oxygen, transcription of the gene is reduced and AdhE is irreversibly inactivated by MCO. The physiological significance of the protection of AdhE by IbpA/B chaperones against MCO is a question which needs to be addressed. One can imagine that maintainence of active AdhE may be an advantage for fast adaptation of aerobically growing cells to new, anoxic conditions. IbpA/B may not only decrease protein oxidation but also prevent other toxic effects of copper. It was found that the $\Delta i b p A / B$ mutation causes increased membrane fluidity and permeability under heat-stress conditions (Nakamoto \& Vigh, 2007). Therefore, it is possible that IbpA/B stabilize and protect the inner membrane in cells exposed to copper.

In summary, we have gained new insights into the role of IbpA/B in protection of $E$. coli cells against oxidative stress induced by copper. We have demonstrated that IbpA/B are molecular chaperones preventing inactivation of a fermentative enzyme, AdhE, by copper-mediated oxidation. Further studies are necessary to explain the mechanism of AdhE protection by $\mathrm{IbpA} / \mathrm{B}$ against metal-catalysed oxidation.

\section{ACKNOWLEDGEMENTS}

This work was supported by grant 0401/P04/2005/28 from the Polish Ministry of Science and Higher Education. We thank Professor Barbara Lipińska for discussions and critical reading of the manuscript.

\section{REFERENCES}

Allen, S. P., Polazzi, J. O., Gierse, J. K. \& Easton, A. M. (1992). Two novel heat shock genes encoding proteins produced in response to heterologous protein experession in Escherichia coli. J Bacteriol 174, 6938-6947.

Avery, S. V., Howlett, N. G. \& Radice, S. (1996). Copper toxicity towards Saccharomyces cerevisiae: dependence on plasma membrane fatty acid composition. Appl Environ Microbiol 62, 3960-3966.

Bradford, M. M. (1976). A rapid and sensitive method for the quantitation of microgram quantities of protein utilizing the principle of protein-dye binding. Anal Biochem 72, 248-254.

Cecarini, V., Gee, J., Fioretii, E., Amici, M., Angeletti, M., Eleuteri, A. M. \& Keller, J. N. (2007). Protein oxidation and cellular homeostasis: emphasis on metabolism. Biochim Biophys Acta 1773, 93-104.

DiGiuseppe, P. A. \& Silhavy, T. J. (2003). Signal detection and target gene induction by the CpxRA two-component system. J Bacteriol 185, 2432-2440. 
Dukan, S. \& Nyström, T. (1998). Bacterial senescence: stasis results in increased and differential oxidation of cytoplasmic proteins leading to developmental induction of the heat shock regulon. Genes Dev 12, 3431-3441.

Echave, P., Esparca-Ceron, M. A., Cabiscol, E., Tamarit, J., Ros, J., Membrillo-Hernández, J. \& Lin, E. C. C. (2002). DnaK dependence of mutant ethanol oxidoreductases evolved for aerobic function and protective role of the chaperone against protein oxidative damage in Escherichia coli. Proc Natl Acad Sci U S A 99, 4626-4631.

Egler, M., Grosse, C., Grass, G. \& Nies, D. H. (2005). Role of extracytoplasmic function protein family sigma factor RpoE in metal resistance of Escherichia coli. J Bacteriol 187, 2297-2307.

Fredriksson, A., Ballesteros, M., Dukan, S. \& Nyström, T. (2005). Defence against protein carbonylation by DnaK/DnaJ and proteases of the heat shock regulon. J Bacteriol 187, 4207-4213.

Ganadu, M. L., Aru, M., Mura, G. M., Coi, A., Mlynarz, P. \& Kozlowski, H. (2004). Effects of divalent metal ions on the alphaBcrystallin chaperone-like activity: spectroscopic evidence for a complex between copper(II) and protein. J Inorg Biochem 98, 1103-1109.

Geuskens, V., Mhammedi-Alaoui, A., Desmet, L. \& Toussaint, A. (1992). Virulence in bacteriophage $\mathrm{Mu}$ : a case of transdominant proteolysis by the Escherichia coli Clp serine protease. EMBO J 11, 5121-5127.

Grass, G. \& Rensing, C. (2001). Genes involved in copper homeostasis in Escherichia coli. J Bacteriol 183, 2145-2147.

Haslbeck, M., Franzmann, T., Weinfurtner, D. \& Buchner, J. (2005). Some like it hot: the structure and function of small heat-shock proteins. Nat Struct Mol Biol 12, 842-846.

Hiniker, A., Collet, J. F. \& Bardwell, J. C. (2005). Copper stress causes an in vivo requirement for the Escherichia coli disulfide isomerase DsbC. J Biol Chem 280, 33785-33791.

Jiao, W., Li, P., Zhang, J., Zhang, H. \& Chang, Z. (2005). Small heatshock proteins function in the insoluble protein complex. Biochem Biophys Res Commun 335, 227-231.

Kershaw, C. J., Brown, N. L., Constantinidou, C., Patel, M. D. \& Hobman, J. L. (2005). The expression profile of Escherichia coli K-12 in response to minimal, optimal and excess copper concentrations. Microbiology 151, 1187-1198.

Kessler, D., Herth, W. \& Knappe, J. (1992). Ultrastructure and pyruvate formate-lyase radical quenching property of the multienzymic AdhE protein of Escherichia coli. J Biol Chem 267, 1807318079.

Kitagawa, M., Miyakawa, M., Matsumura, Y. \& Tsuchido, T. (2000). Small heat shock proteins, IbpA and IbpB, are involved in resistances to heat and superoxide stress in Escherichia coli. FEMS Microbiol Lett 184, 165-171.

Kitagawa, M., Miyakawa, M., Matsumura, Y. \& Tsuchido, T. (2002), Escherichia coli small heat shock proteins, IbpA and IbpB, protect enzymes from inactivation by heat and oxidants. Eur J Biochem 269, 2907-2917.

Kucharczyk, K., Laskowska, E. \& Taylor, A. (1991). Response of Escherichia coli cell membranes to induction of lambda cl857 prophage by heat shock. Mol Microbiol 5, 2935-2945.

Kuczyńska-Wiśnik, D., Kędzierska, S., Matuszewska, E., Lund, P., Taylor, A., Lipińska, B. \& Laskowska, E. (2002). The Escherichia coli small heat-shock proteins IbpA and IbpB prevent the aggregation of endogenous proteins denatured in vivo during extreme heat shock. Microbiology 148, 1757-1765.

Laemmli, U. K. (1970). Cleavage of structural proteins during the assembly of the head of bacteriophage T4. Nature 227, 680-685.
Laskowska, E., Wawrzynów, A. \& Taylor, A. (1996). IbpA and IbpB, the new heat shock proteins, bind to endogenous Escherichia coli proteins aggregated intracellularly by heat shock. Biochimie 78, $117-122$.

Laskowska, E., Kuczyńska-Wiśnik, D., Bąk, M. \& Lipińska, B. (2003). Trimethoprim induces heat shock proteins and protein aggregation in E. coli cells. Curr Microbiol 47, 286-289.

Macomber, L., Rensing, C. \& Imlay, J. A. (2007). Intracellular copper does not catalyze the formation of oxidative DNA damage in Escherichia coli. J Bacteriol 189, 1616-1626.

Matayoshi, S., Oda, H. \& Sarwar, G. (1989). Relationship between the production of spirosomes and anaerobic glycolysis activity in Escherichia coli B. J Gen Microbiol 135, 525-529.

Matuszewska, M., Kuczyńska-Wiśnik, D., Laskowska, E. \& Liberek, K. (2005). The small heat shock protein IbpA from Escherichia coli cooperates with $\mathrm{IbpB}$ in stabilization of thermally aggregated proteins in a disaggregation competent state. J Biol Chem 280, 12292-12298.

Membrillo-Hernández, J., Echave, P., Cabiscol, E., Tamarit, J., Ros, J. \& Lin, E. C. C. (2000). Evolution of the adhE gene product of Escherichia coli from a functional reductase to a dehydrogenase. Genetic and biochemical studies of the mutant proteins. J Biol Chem 275, 33869-33875.

Mogk, A., Tomoyasu, T., Goloubinoff, P., Rüdiger, S., Röder, D., Langen, H. \& Bukau, B. (1999). Identification of thermolabile Escherichia coli proteins: prevention and reversion of aggregation by DnaK and ClpB. EMBO J 18, 6934-6949.

Mogk, A., Deuerling, E., Vorderwülbecke, S., Vierling, E. \& Bukau, B. (2003a). Small heat shock proteins, ClpB and the DnaK system form a functional triade in reversing protein aggregation. Mol Microbiol 50, 585-595.

Mogk, A., Schlieker, C., Friedrich, K. L., Schönfeld, H. J., Vierling, E. \& Bukau, B. (2003b). Refolding of substrates bound to small Hsps relies on a disaggregation reaction mediated most efficiently by ClpB/DnaK. J Biol Chem 278, 31033-31042.

Moschini, R., Marini, I., Malerba, M., Cappiello, M., Del Corso, A. \& Mura, U. (2006). Chaperone-like activity of $\alpha$-crystallin toward aldose reductase oxidatively stressed by copper ion. Arch Biochem Biophys 453, 13-17.

Nakamoto, H. \& Vigh, L. (2007). The small heat shock proteins and their clients. Cell Mol Life Sci 64, 294-306.

Narberhaus, F. (2002). $\alpha$-Crystallin-type heat shock proteins: socializing minichaperones in the context of a multichaperone network. Microbiol Mol Biol Rev 66, 64-93.

Nnyepi, M. R., Peng, Y. \& Broderick, J. B. (2007). Inactivation of E. coli pyruvate formate-lyase: role of AdhE and small molecules. Arch Biochem Biophys 459, 1-9.

Nyström, T. (2005). Role of oxidative carbonylation in protein quality control and senescence. EMBO J 24, 1311-1317.

Outten, F. W., Huffman, D. L., Hale, J. A. \& O'Halloran, T. V. (2001). The independent cue and cus systems confer copper tolerance during aerobic and anaerobic growth in Escherichia coli. J Biol Chem 276, 30670-30677.

Pérez, J. M., Calderón, I. L., Arenas, F. A., Fuentes, D. E., Pradenas, G. A., Fuentes, E. L., Sandoval, J. M., Castro, M. E., Elías, A. O. \& Vásquez, C. C. (2007). Bacterial toxicity of potassium tellurite: unveiling an ancient enigma. PLoS ONE 2, e211.

Silver, S. \& Phung, L. T. (2005). A bacterial view of the periodic table: genes and proteins for toxic inorganic ions. J Ind Microbiol Biotechnol 32, 587-605.

Stadtman, E. R. (1991). Ascorbic acid and oxidative inactivation of proteins. Am J Clin Nutr 54, 1125S-1128S. 
Storz, G. \& Imlay, J. A. (1999). Oxidative stress. Curr Opin Microbiol 2, 188-194.

Suwalsky, M., Ungerer, B., Quevedo, L., Aguilar, F. \& Sotomayor, C. P. (1998). $\mathrm{Cu}^{2+}$ ions interact with cell membranes. J Inorg Biochem 70, 233-238.

Tamarit, J., Cabiscol, E. \& Ros, J. (1998). Identification of the major oxidatively damaged proteins in Escherichia coli cells exposed to oxidative stress. J Biol Chem 273, 3027-3032.

Tree, J. J., Kidd, S. P., Jennings, M. P. \& McEwan, A. G. (2005). Copper sensitivity of cueO mutants of Escherichia coli K-12 and the biochemical suppression of this phenotype. Biochem Biophys Res Commun 328, 1205-1210.
Veinger, L., Diamant, S., Buchner, J. \& Goloubinoff, P. (1998). The small heat-shock protein IbpB from Escherichia coli stabilizes stressdenatured proteins for subsequent refolding by a multichaperone network. J Biol Chem 273, 11032-11037.

Winter, J., Linke, K., Jatzek, A. \& Jakob, U. (2005). Severe oxidative stress causes inactivation of DnaK and activation of the redoxregulated chaperone Hsp33. Mol Cell 17, 381-392.

Yamamoto, K. \& Ishihama, A. (2005). Transcriptional response of Escherichia coli to external copper. Mol Microbiol 56, 215227.

Edited by: D. J. Jamieson 